\title{
Barriers to quality patient care in rural district hospitals
}

\author{
Authors: \\ Johanna E. Eygelaar ${ }^{1}$ \\ Ethelwynn L. Stellenberg ${ }^{1}$ \\ Affillliations: \\ ${ }^{1}$ Faculty of Health Sciences, \\ Stellenbosch University, \\ South Africa \\ Correspondence to: \\ Ethelwynn Stellenberg \\ Email: \\ elstel@sun.ac.za \\ Postal address: \\ PO Box 19063, Tygerberg \\ 7500 , South Africa \\ Dates: \\ Received: 18 Feb. 2012 \\ Accepted: 20 Feb. 2012 \\ Published: 09 May 2012 \\ How to cite this article: \\ Eygelaar, J.E. \& Stellenberg, \\ E.L., 2012, 'Barriers to \\ quality patient care in rural \\ district hospitals', Curationis \\ 35(1), Art. \#36, 8 pages. \\ http://dx.doi.org/10.4102/ \\ curationis.v35i1.36
}

C 2012. The Authors

Licensee: AOSIS

OpenJournals. This work

is licensed under the

Creative Commons

Attribution License.
Currently barriers exist in delivering quality health care. This study aimed to investigate such barriers in the eight rural district hospitals of the West Coast Winelands Region, three type A and five type B hospitals.

A quantitative descriptive design was applied which included the total population of nursing staff $(n=340)$ working at the time of data collection. A self-administered questionnaire was distributed with a response rate of $82 \%$.

Reliability of the instrument was verified using the Cronbach alpha coefficient and a pilot study. The validity, specifically construct and content validity, were assured by means of an extensive literature review, pilot study and use of experts. Ethics approval was obtained from the relevant stakeholders.

Results showed that 272 participants (97\%) disagreed that provision of staff was adequate, with staff above 40 years of age more likely to disagree $(p=<0.01)$. A statistically significant association was shown between availability of doctors and staff not being able to cope with emergencies ( $p=<0.01)$. Most participants $(n=212 ; 76 \%)$ indicated that they were not receiving continuing education, with the registered nurses more likely to disagree $\left(\chi^{2}\right.$ test, $p=0.02$ ). Participants in both hospital types A $(n=131 ; 82 \%)$ and B $(n=108 ; 91 \%)$ also disagreed that provision of equipment and consumables was adequate.

The research showed that inadequacies relating to human resources, professional development, consumables and equipment influenced the quality of patient care. Urgent attention should be given to the problems identified to ensure quality of patient care in rural hospitals.

\section{Introduction}

The World Health Organization's (WHO) objective, as set out in its Constitution, is attainment of the highest possible level of health for all people (WHO 2002:2). The Constitution of South Africa (Act 106 of 1996) is aligned with this objective, and emphasises the right to basic health. The South African Government is therefore under obligation to assist with realisation of the right to basic health care, as described in the White Paper on Transforming Public Service Delivery in South Africa (Department of Public Service and Administration 1997). The WHO (2002:2) holds governments responsible for the "health of their people which can be fulfilled only by the provision of adequate health and social measures."

According to the National Patient Rights Charter (Department of Health 1999) and Batho Pele Principles (Department of Public Service and Administration 1997) it is expected of nursing staff that they put patients first and deliver a quality health care service. Furthermore, according to the Nursing Act 33 of 2005, Regulations 2598, Scope of Practice, and 387, Acts and Omissions, as promulgated by the Nursing Act 50 of 1978, the nurse practitioner is held responsible and accountable for all acts and omissions in the delivery of quality patient care.

It has been observed that the nursing profession is experiencing barriers in delivering quality health care, such as a shortage of staff (Aiken et al. 2002, 1987-1993; Richardson 2011:1-16; Wildschut \& Mqolozana 2008:2), equipment (Couper, Thurley \& Hugo 2005:1; Xego, 2006:33) and continuous professional development (Deaton, Essenpreis \& Simpson 1998:34). In a research report commissioned by the Department of Labour, a shortage of professional nurses, including a skills deficit within the nursing profession, was identified (Wildschut \& Mqolozana 2008:2). Only 222 registered professional nurses service every 100000 South Africans (Solidarity Research Institute 2009:4-5). The 2008 South African Democratic and Health Survey showed that this shortage of nurses is more pronounced in rural areas (Rural Doctor's Association of Southern Africa (RUDASA), 2008:5). 
According to the RUDASA (2008:1), very little consensus exists as to what constitutes a rural area. It could be defined in terms of inadequate access to health services, because it is situated outside of cities and towns and characterised by farms, low population density and poor basic services such as electricity and water. Rural areas in developing countries tend to be the most underserved (WHO 2009:3).

Booyens (1998:596-597) identified several dimensions of quality, in terms of appropriateness, accessibility, effectiveness, efficiency, equity and acceptability. Couper (2004:1) described quality improvement as an important part of developing rural health services. According to Kenny and Duckett (2003:619), internationally it has been argued that policy-makers do not acknowledge the differences between health care delivery in rural areas and in urban ones. Nurses in rural areas fulfill an extremely comprehensive, multi-skilled role, but are often inadequately prepared for it. In the rural areas nursing practices are often carried out in the absence of other health professionals, particularly doctors. Amalgamated services, downsizing and shortened hospital stays have all resulted in nurses in rural and remote communities having to care for patients with more complex problems.

Therefore hospital services in rural areas require nurses to maintain critical thinking and evaluation skills and use good decision-making skills. Courtney et al. (2002:11) found that the majority of rural and remote nursing executives identified distance, cost, lack of time and problems with access, support and relieving staff as barriers to their professional development. Lack of professional and educational opportunities was an important factor preventing their continuation in rural nursing. Currently in practice, the principal investigator has observed that in rural hospitals as described in this study, only one professional nurse, staff nurse and auxilliary are allocated per shift, per ward.

An evaluation of quality of nursing care in Swaziland showed that most nurses (75\%), lodgers (parents staying with their children in hospital) and clients or patients concurred that quality of nursing care was not at an acceptable level (Shongwe 2000). The nurses perceived severe shortages of nurses, equipment and medical supplies and nurses' poor working conditions to be the main problems underlying the poor quality of nursing care. In a study by Xego (2006:33), respondents described the shortage of equipment, especially of beds, bedside lockers, medical equipment like blood pressure machines, and bed linen as highly stressful. According to Couper et al. (2005:1), in-service training in neonatal resuscitation for nurses in rural areas was seriously hampered due to serious deficiencies in neonatal resuscitation equipment such as laryngoscope blades.

\section{Problem statement}

The principal investigator worked in one of these hospitals as a Nursing Service Manager, and identified that the quality of nursing care was seriously compromised by a shortage of staff, part-time doctors, increasing workloads due to shortage of staff, and inadequate equipment and provisions, which directly influenced the execution of nursing care.

It was against this background that the researcher identified the need for a scientific investigation into the factors influencing the quality of nursing care in the identified rural hospitals.

\section{Research question}

The research question which guided this research was: What are the factors influencing the quality of nursing care in rural district hospitals in the West Coast Winelands Region of the Western Cape?

\section{Goal of the study}

The goal of the study was to identify the factors which influence the quality of nursing care in the eight rural district hospitals of the West Coast Winelands Region.

\section{Objectives}

The objectives of the study were to determine whether:

- staffing was adequate for all the nursing activities;

- adequate professional development opportunities were available;

- absence of full-time doctors influenced management of patient care; and

- adequate equipment and consumables were available for execution of nursing care.

\section{Concept definitions}

Barriers: Refers to inadequate staffing, opportunities for professional development, absence of full- time doctors and equipment and consumables as identified by the nursing staff. A barrier is defined by Webster's New World College Dictionary as anything that is a hindrance to progress (Agnes 2004).

Emergency: A perilous situation that arises suddenly and threatens the life or welfare of a person or a group of people, such as a natural disaster, medical crisis, or trauma situation (Anderson 2002).

Staff nurse: A person educated to practise basic nursing in the manner and to the level prescribed (Nursing Act 33 of 2005:25).

Auxilliary nurse: A person educated to provide elementary nursing care in a manner and to the level prescribed (Nursing Act 33 of 2005:25).

Quality: May be defined as fitness to serve, correct service the first time to meet customers' needs, and freedom from deficiencies (Roussel \& Swansburg 2009:527).

Professional nurse: A person who is qualified and competent to independently practice comprehensive nursing in the 
manner and to the level prescribed and who is capable of assuming responsibility and accountability for such practice (Nursing Act 33 of 2005:25).

Rural district hospital: A facility at which a range of outpatient and inpatient services are offered, 24 hours a day, 7 days a week. Bed composition varies between 30 and 200 and includes a 24-hour emergency service and an operating theatre, referred to as the first level of referral (Cullinan 2006:12), situated either in a rural or urban setting.

Type A hospitals: are larger hospitals with more than 50 beds and wards accommodating only one discipline, such as only patients with obstetric conditions.

Type B hospitals: are smaller hospitals with less than 50 beds and wards accommodating all types of disciplines, such as general medical, surgical, paediatrics and/or obstetric cases.

\section{Significance of the study}

The research upon which this article is based identified factors which influence the quality of nursing care in the rural hospitals, and thus provides scientific evidence for policy makers in health and specifically the District Health System when formulating policy for rural health.

\section{Theoretical framework}

Donabedian's tripartite model (1980) which addresses three domains, namely structure, process and outcome, was applied in this study.

Structure refers to the required resources, such as staff, equipment, infrastructure, policies and finances which enable a health care service to deliver patient care (Donabedian 1980:1). Process refers to the treatment process, which includes interpersonal process factors and technical skills in the delivery of a service.

Donabedian (1980:82) refers to outcome as "a change in the patient's current and future health status (symptoms and functioning) that can be attributed to antecedent health care. Outcome may also include attitudes of patients."

According to Uys (2004:25), these components are interdependent. For the purposes of this research the structure as described by Donabedian (1980) was researched in the region as identified.

\section{Research method and design Design}

A descriptive quantitative design was applied to investigate the factors which influence the quality of nursing care in the context of the rural district hospitals of the West Coast Winelands Region. This design was most appropriate since there was no intervention or treatment; the purpose was to determine and describe existing barriers to patient care.

\section{Population and sampling}

The study included the total population $(n=346)$, but excluded staff on leave $(n=6)$ at the time of data collection. The final population consisted of 340 nursing staff, and the response rate was 280 out of 340 or $82 \%$.

\section{Inclusion criteria}

All nursing staff (management, professional nurses, staff nurses and auxilliary nurses) on duty at the time of data collection voluntarily participated in the study with informed consent. Only nurses working at the hospitals under study were included.

\section{Instrument and data collection}

A questionnaire was designed based on the literature, experience of the researchers and objectives set for the study. The questionnaire was divided into a biographical section (A) referring to gender, age, categories of staff, qualifications, experience, and the type of ward, hospital and duration of working in the particular ward. Section (B) was based on a Likert scale design with four options to choose from, namely: strongly disagree, disagree, agree and strongly agree. The questionnaire consisted of predominantly closedended questions, and participants were given the option of providing comments on each subsection. The subsection on provision of staff consisted of 8 questions, that on professional development of 3 questions, and that on consumables and equipment of 4 questions. A self-administered questionnaire was personally distributed to the participants between July and August 2008, and was returned via land post to the researcher. The researcher covered all expenses.

\section{Pilot study}

A pilot study was conducted to refine the methodology applied to the larger study. This was to ensure the success, effectiveness and feasibility of the investigation. Participants $(n=35 ; 10 \%)$ of the actual study from two rural hospitals participated in the pilot study. No changes were made to any of the questions as the questionnaire was found to be relevant for the purpose of the study, free of errors, and participants understood all questions. The results of the pilot study were not included in the main study.

\section{Data analysis}

Data are presented in frequencies and tables. Comparisons between variables were made using either ANOVA (analysis of variance) techniques or cross-tabulations on a $95 \%$ confidence interval to determine associations of statistical significance. Guided by the statistician, the four options (namely strongly disagree, disagree, agree and strongly agree) were collapsed into disagree and agree.

\section{Results}

\section{Section A: Personal data}

Most participants were female $(n=272 ; 97 \%)$ and above 40 years of age $(n=168 ; 60 \%)$. Categories of nursing staff who 
participated included management $(n=13 ; 5 \%)$, registered nurses $(n=93 ; 33 \%)$, staff nurses $(n=73 ; 26 \%)$ and auxilliary nurses $(n=101 ; 36 \%)$.

Only $33(12 \%)$ of the professional nurses $(n=106 ; 38 \%)$ were in possession of a specialised qualification (e.g. Primary Health Care or Advanced Midwifery), which is required for advanced skills in the absence of full-time appointed doctors. The type B hospitals, in which the wards accommodated all specialties, required nurses with advanced skills since a variety of conditions were managed in the wards.

\section{Section B: Barriers influencing quality of nursing care}

Subsection 1: Issues related to provision of staff (Table 1)

Provision of staff is inadequate (in numbers) for all nursing care functions $(\boldsymbol{n}=279)$ : Participants $(n=272 ; 97 \%)$ disagreed that provision of staff was adequate in numbers for all nursing care functions. A significant difference between age and staff provision was identified (Spearman test, $p=<0.01$ ), with staff above 40 years of age more likely to indicate that provision of staff was inadequate for the workload of nursing care.

Provision of staff is inadequate in terms of comprehensive skills $(n=275)$ : The results showed that participants $(n=263$; $96 \%$ ) disagreed that provision of staff was adequate in terms of comprehensive skills. It was required that staff members be widely skilled to enable them to function in a variety of settings. A significant difference was identified between age and outlook on staff provision in terms of comprehensive skills (Spearman test, $p=0.02$ ), with older staff more likely to indicate that provision here was inadequate.

Nursing functions delegated to subordinates are not adequately supervised $(n=272)$ : Participants $(n=226$; $83 \%$ ) disagreed that all nursing functions delegated were 'adequately supervised' (which in the context of this study referred to wards that received supervision during office and after hours). It was identified that type B hospitals did not have full-time operational nurse managers to supervise after hours, this being limited to office hours, Monday to Friday. A significant difference was identified between hospital type and supervision of subordinates $\left(\chi^{2}\right.$ test, $\left.p=0.04\right)$, with those from type $B$ hospitals more likely to disagree that supervision was adequate.

According to Searle (2005:206) all duties delegated to subordinates or peer-group personnel must be supervised,
TABLE 1: Provision of staff.

\begin{tabular}{|c|c|c|c|c|c|c|}
\hline \multirow{2}{*}{ Provision of staff } & \multicolumn{2}{|c|}{ Agree } & \multicolumn{2}{|c|}{ Disagree } & \multicolumn{2}{|c|}{ Total } \\
\hline & $n$ & $\%$ & $n$ & $\%$ & $N$ & $\%$ \\
\hline $\begin{array}{l}\text { Provision of staff is adequate } \\
\text { (in numbers) }\end{array}$ & 7 & 3 & 272 & 97 & 279 & 100 \\
\hline $\begin{array}{l}\text { Provisions of staff is adequate } \\
\text { (in terms of skills) for each } \\
\text { department in the hospital }\end{array}$ & 12 & 4 & 263 & 96 & 275 & 100 \\
\hline $\begin{array}{l}\text { All nursing functions delegated } \\
\text { are adequately supervised }\end{array}$ & 46 & 17 & 226 & 83 & 272 & 100 \\
\hline
\end{tabular}

Source: Eygelaar \& Stellenberg

for the registered practitioner in charge of the particular health care institution retains responsibility for the duties delegated to another registered person under her supervision, and is accountable for the way in which delegated duties are performed, even though the subordinates or peergroup personnel retain their own level of responsibility and accountability.

\section{Subsection 2: Availability of Doctors (Table 2)}

Doctors full-time in hospitals $(n=201)$ : Participants at both types of hospitals, type A $(n=83 ; 52 \%)$ and B $(n=118$; $98 \%$ ), disagreed that full- time doctors were available in the hospitals. A statistically significant difference was identified between hospital type and having full-time doctors available (Chi-square and Mann-Whitney tests, $p=<0.01$ ): type A hospitals had the benefit of full-time employed doctors while type B hospitals only employed doctors on a session basis. Nursing staff reported that with doctors present patients were getting appropriate investigations, accurate diagnoses and correct treatment, leading to the patients healing faster and therefore leaving hospital faster. In addition, nursing staff experienced less stress with doctors present in the hospital.

Staff always able to cope with medical emergencies ( $n=212)$ : Participants in both types of hospitals, type A $(n=110 ; 69 \%)$ and $\mathrm{B}(n=102 ; 85 \%)$, disagreed that staff were always able to cope with medical emergencies; this was due to unavailability of doctors. A statistically significant difference was identified between hospital type here $\left(\chi^{2}\right.$ test, $p=<0.01$ ), with type B hospitals more likely to disagree that staff were able to cope with medical emergencies.

Staff always able to cope with trauma emergencies ( $n=207)$ : In both types of hospitals, A $(n=109 ; 69 \%)$ and B ( $n=98 ; 82 \%)$, participants disagreed that staff were always

TABLE 2: Availability of doctors.

\begin{tabular}{|c|c|c|c|c|c|c|c|c|}
\hline \multirow[t]{3}{*}{ Availability of doctors } & \multicolumn{4}{|c|}{ Type A hospitals $(n=160)$} & \multicolumn{4}{|c|}{ Type B hospitals $(n=120)$} \\
\hline & \multicolumn{2}{|c|}{ Agree } & \multicolumn{2}{|c|}{ Disagree } & \multicolumn{2}{|c|}{ Agree } & \multicolumn{2}{|c|}{ Disagree } \\
\hline & $n$ & $\%$ & $n$ & $\%$ & $n$ & $\%$ & $N$ & $\%$ \\
\hline Doctors full time in hospital & 77 & 48 & 83 & 52 & 2 & 2 & 118 & 98 \\
\hline Staff are always able to cope with medical emergencies & 50 & 31 & 110 & 69 & 18 & 15 & 102 & 85 \\
\hline Staff are always able to cope with trauma emergencies & 51 & 32 & 109 & 68 & 22 & 18 & 98 & 82 \\
\hline Staff are able to cope with maternity emergencies & 50 & 31 & 110 & 69 & 28 & 23 & 92 & 77 \\
\hline In cases of emergency, doctors are immediately available & 56 & 35 & 104 & 65 & 23 & 19 & 97 & 81 \\
\hline
\end{tabular}

Source: Eygelaar \& Stellenberg 
able to cope with trauma emergencies due to absence of doctors. A statistical association was identified between years of experience at the institution and opinion on this $\left(\chi^{2}\right.$ test, $p=0.03$ ); staff with more than 10 years' working experience were more likely to disagree that they were able to cope in the absence of doctors. Also statistically significant $\left(\chi^{2}\right.$ test, $p=<0.01$ ) was that participants of type B hospitals were more likely to disagree that they were able to cope in the absence of doctors.

Staff able to cope with maternity emergencies $(n=202)$ : Participants in both types of hospitals, A $(n=110 ; 69 \%)$ and $\mathrm{B}(n=92 ; 77 \%)$, disagreed that staff were always able to cope with maternity emergencies in the absence of doctors, but no significant result was obtained.

In cases of emergency, doctors are immediately available $(n=201)$ : In both types of hospitals, A $(n=104 ; 65 \%)$ and B $(n=97 ; 81 \%)$, participants disagreed that doctors were immediately available in cases of emergency. A statistically significant correlation was identified between hospital type ( $\chi^{2}$ test, $p=<0.01$ ), with type B hospitals more likely to disagree about availability of doctors in cases of emergency.

\section{Subsection 3: Professional development (Table 3)}

Staff receiving continuing education $(n=278)$ : Participants disagreed $(n=212 ; 76 \%)$ that staff were receiving continuing education. A statistically significant difference was identified between category of participants and staff receiving continuing education $\left(\chi^{2} p=0.02\right)$, with the registered nurses more likely to disagree that they were receiving continuing education.

Staff have adequate opportunities for career development ( $n=276)$ : Participants $(n=254 ; 92 \%)$ disagreed that there were adequate opportunities for career development. The Spearman test showed a statistically significant difference between age here $(p=0.03)$, with participants in the age group 40-50 years more likely to disagree that there were adequate opportunities for career development. Further analysis identified a statistically significant difference between hospital type and professional development (MannWhitney test, $p<0.01$ ), with type A hospitals more likely to develop their staff than type B hospitals.

Staff members are qualified to cope in all ward settings $(n=269)$ : Most participants $(n=236 ; 88 \%)$ disagreed that there was an adequate number of staff who were qualified to cope in all ward settings. A statistically significant difference
TABLE 3: Professional Development.

\begin{tabular}{|c|c|c|c|c|c|c|}
\hline \multirow[t]{2}{*}{ Professional development } & \multicolumn{2}{|c|}{ Agree } & \multicolumn{2}{|c|}{ Disagree } & \multicolumn{2}{|c|}{ Total } \\
\hline & $n$ & $\%$ & $n$ & $\%$ & $N$ & $\%$ \\
\hline Receiving continuing education & 66 & 24 & 212 & 76 & 278 & 100 \\
\hline $\begin{array}{l}\text { Staff have adequate } \\
\text { opportunities for career } \\
\text { development }\end{array}$ & 22 & 8 & 254 & 92 & 276 & 100 \\
\hline $\begin{array}{l}\text { Staff members are qualified to } \\
\text { cope in all the departments, } \\
\text { e.g. primary health care or in } \\
\text { theatre }\end{array}$ & 33 & 12 & 236 & 88 & 269 & 100 \\
\hline
\end{tabular}

Source: Eygelaar \& Stellenberg

was identified between hospital type and adequate number of staff members qualified to cope in all the departments $\left(\chi^{2}\right.$ test, $\left.p=<0.01\right)$, with those from type A hospitals more likely to agree that staff were qualified to cope in all ward settings. The qualification of primary health care was identified as a need, especially in the type B hospitals where only part-time doctors were employed, resulting in staff having to manage all primary health care patients after hours. Management of patients without the required skills may result in legal implications.

\section{Subsection 4: Equipment and consumables (Table 4)}

Equipment and consumables are always adequate $(n=239)$ : Participants in the different hospital types, A $(n=131$; $82 \%)$ and $\mathrm{B}(n=108 ; 91 \%)$, disagreed about the adequacy of equipment and consumables. A statistically significant difference was identified here $\left(\chi^{2}\right.$ test, $\left.p=0.04\right)$, with those in type $\mathrm{B}$ hospitals more likely to disagree that equipment and consumables were adequate.

Equipment is always in working condition $(n=242)$ : Participants from both hospital types, A $(n=133 ; 84 \%)$ and B ( $n=109 ; 92 \%)$, disagreed that equipment was always in working condition.

Maintenance of equipment is done on a regular basis ( $n=232)$ : In both hospital types, A $(n=126 ; 79 \%)$ and B ( $n=106 ; 90 \%)$, participants disagreed that maintenance of equipment was done on a regular basis. A statistical significant difference was identified here $\left(\chi^{2}\right.$ test, $\left.p=0.01\right)$, with type B hospitals more likely to disagree. Maintaining equipment in good working condition is the responsibility of each member of staff working with such equipment (Booyens 2001:270). Maintained equipment is needed to render safe nursing care.

Adequate consumables are available to prevent crossinfection ( $n=217)$ : Participants from both hospital types, A $(n=119 ; 74 \%)$ and $\mathrm{B}(n=98 ; 82 \%)$, disagreed that consumables

\begin{tabular}{|c|c|c|c|c|c|c|c|c|}
\hline \multirow[t]{3}{*}{ Equipment and consumables } & \multicolumn{4}{|c|}{ Type A hospitals $(n=160)$} & \multicolumn{4}{|c|}{ Type B hospitals $(n=120)$} \\
\hline & \multicolumn{2}{|c|}{ Agree } & \multicolumn{2}{|c|}{ Disagree } & \multicolumn{2}{|c|}{ Agree } & \multicolumn{2}{|c|}{ Disagree } \\
\hline & $n$ & $\%$ & $N$ & $\%$ & $n$ & $\%$ & $n$ & $\%$ \\
\hline Equipment and consumables are always adequate & 29 & 18 & 131 & 82 & 12 & 9 & 108 & 91 \\
\hline Equipment is always in working condition & 27 & 17 & 133 & 83 & 11 & 8 & 109 & 92 \\
\hline Maintenance of equipment is done on a regular basis & 34 & 21 & 126 & 79 & 14 & 10 & 106 & 90 \\
\hline $\begin{array}{l}\text { Adequate consumables are available to prevent cross-infection } \\
\text { and measures are always strictly maintained }\end{array}$ & 41 & 26 & 119 & 74 & 22 & 18 & 98 & 82 \\
\hline
\end{tabular}


were always available according to predetermined consumable norms to ensure that cross-infection measures were always maintained. The Spearman test found a significant difference between age and this variable $(p=<0.01)$, with older staff more likely to disagree with the adequacy of consumables.

\section{Ethical considerations}

Ethics clearance was obtained from the Human Research Ethics Committee of the university where the study was registered (certificate number N08/05/129). Permission to conduct the research within the hospital region was obtained from Provincial Government and participating hospitals.

Information sessions were held at each hospital under study where the participants were invited to take part. A participation information leaflet was attached to each questionnaire. Contact details of the researcher were made available to participants in the event of any queries.

Individual informed written consent was obtained from all the participants, who were assured of their right to confidentiality, anonymity and privacy. Participation was voluntary and participants were free to decline, participate or withdraw without fear that they would be affected adversely. No risks were foreseen from the study.

Collected data were handled in a confidential and protective manner, with access only to the researcher and statistician.

\section{Validity and reliability}

Construct validity, which includes content validity, was ensured through consultation with experts in quality assurance, nursing, research and statistics. The design of the instrument was based on the clinical experience of the researchers and an extensive literature review to determine whether the instrument reflected the abstract concepts being examined and would measure those in question. In addition, a pilot study was conducted to test the reliability and validity of the instrument to ensure its feasibility and readability.

Reliability was further supported by determining the Cronbach alpha coefficient, which varied between 0.71 and 0.86 . This is regarded as the most widely used method for evaluating internal consistency to estimate the extent to which different subparts of an instrument are reliable in measuring the critical attribute (Polit \& Beck 2008:455). External validity is the extent to which study findings can be generalised beyond the sample used in the study (Burns \& Grove 2007:540), and was ensured through application of statistical tests which examined any significant differences between or among groups to enable the results to be generalised.

\section{Discussion}

According to Donabedian (1980:1) three approaches are suggested to assess the quality of patient care, namely structure, process and outcome. The purpose of the research upon which this article is based was to identify the barriers influencing the quality of nursing care with specific reference to the structural approach. The research question of this study was answered and the objectives of the research, to determine whether human resources professional development and provisions and equipment were barriers in delivering quality nursing care, were scientifically investigated.

Ninety-seven per cent of participants indicated that staff allocated to perform all nursing functions was inadequate, while $96 \%$ indicated that the staff were inadequately skilled to perform in a wide range of nursing settings, such as primary health care and trauma. In addition, $83 \%$ indicated that supervision of all nursing functions delegated was inadequate. The study further identified that the availability of doctors was inadequate as they do not function in the hospitals on a full-time basis. Seventy-six per cent of participants indicated that this created an ethical and legal dilemma and placed the patients' safety at risk, since the skills required for management of the various emergencies were inadequate (Eygelaar 2009:80).

The delivery of care is also aggravated by inadequate opportunities to develop staff and inadequate material resources. According to Donabedian (1990:1115) the structural approach not only requires human resources and skills, but emphasises the need for adequate equipment, material resources and facilities to ensure safe delivery of patient care. The majority of participants $(85 \%)$ indicated that material resources to deliver safe nursing care were inadequate.

Ninety-nine per cent of participants in hospital B disagreed that doctors were available full-time in hospitals. These results are supported by Kenny and Duckett (2003:616), who identified that in the rural areas nursing practices are often carried out in the absence of other health professionals, particularly doctors. De Villiers (2004:21) provides evidence that substantial after-hour duties, an excessive workload and a perceived lack of management support impact negatively on doctors' views of working in district hospitals.

Results further showed that $92 \%$ of participants disagreed that adequate opportunities existed for professional development. Courtney et al. (2002:11) substantiate that the majority of rural and remote nursing executives identified barriers which exist in relieving staff for their professional development. The National Patient Rights Charter (Department of Health 1999) and Batho Pele Principles (Department of Public Service and Administration 1997) require that all health care workers put patients first, and deliver quality health care. However, the nursing profession is faced daily with various challenges in delivering quality health care. These include staff shortages, a deficit in skills, increasing workloads and a lack of basic resources, as shown in this study. In rural hospitals the barriers are astronomical and much more intense than in urban hospitals.

Lee and Winters (2006:232) identified that recruitment and retention of nurses in rural practice is challenging and more 
difficult than in urban practice, because of rural wages, scarcity of jobs for spouses, and negative perceptions of rural nursing. In addition, a skills deficit exists within the nursing profession (Wildschut \& Mqolozana 2008:2); the Solidarity Research Institute (2009:4-5) reports that South Africa has only 222 registered nurses for every 100000 people.

The nurse is compelled to function within a legal and ethical framework, and should not be faced with ethical dilemmas in delivering unsafe patient care. According to the Nursing Act (33 of 2005), Regulations 2598, Scope of Practice and 387, Acts and Omissions as promulgated by the Nursing Act (50 of 1978), a professional registered nurse is held accountable and responsible for all acts and omissions. In failing to comply with legislation, a nurse may be subjected to disciplinary action and litigation. Therefore, the nurse's rights to deliver safe patient care should not be jeopardised by inadequate staffing, skills, consumables and equipment. Aiken et al. (2002: 1987-1993) identified that due to inadequate staffing, 232342 patients admitted (23.2\%) developed a complication not present on admission, while $2 \%$ died within 30 days.

According to Searle (2000:364) nurses have the right to expect conditions of employment and practice that enable them to practise in a knowledgeable, competent, legal and ethical manner. In addition, nurses have the right to expect adequate support from management and colleagues in the health team, which will ensure trust from the public they serve.

\section{Limitations of the study}

This research was limited to rural district hospitals in one region of the Western Cape Province only.

\section{Recommendations}

Recommendations based on the results of the research include the following:

- Adequate provision of qualified nursing staff who are skilled in the various specialties required in the rural hospitals.

- Supervisors should be constantly aware of the strengths and abilities of nursing staff. Continuous professional development and in-service training are essential to ensure that nurses are skilled and competent in their daily clinical practice.

- Introduction of full-time doctors and availability of doctors for emergencies should be addressed urgently.

- Provision of an adequate supply of consumables and wellmaintained and essential equipment is a prerogative for quality patient care.

Further research is recommended in the field of rural nursing.

\section{Conclusion}

This research study successfully identified the inadequacies which exist in staffing, professional development opportunities, equipment and consumables, and the absence of full-time doctors which may influence the management of quality nursing care in the eight rural district hospitals in the West Coast Winelands Region.

\section{Acknowledgements}

Thanks to Dr E.L. Stellenberg from the Faculty of Health Sciences, University of Stellenbosch, for continuous support, guidance and encouragement as supervisor throughout the study. The researcher would also like to extend her appreciation to the University of Stellenbosch for granting her with the Kate van Rensburg Bursary for Postgraduate Studies as well as the Provincial Government of the Western Cape for granting a bursary during 2007 and 2008.

\section{Competing interest}

The authors declare that they have no financial or personal relationships which may have inappropriately influenced them in writing this article.

\section{Authors' contributions}

The researcher is very grateful to E.L.S, Stellenbosch University who kindly invested her time and expertise in supporting the researcher in the drafting of this article.

\section{References}

Agnes, M.E., ed., 2004, Webster's New World College Dictionary, viewed 12 February 2012, from http://www.yourdictionary.com/barrier

Aiken, L.H., Clarke, S.P., Sloane, D.M., Sochalski., J. \& Silber, J.H., 2002, 'Hospital Nurse Staffing and Patient Mortality, Nurse Burnout, and Job Dissatisfaction', Journal of the American Medical Association 288(16), 1987-1993. http://dx.doi. org/10.1001/jama.288.16.1987

Anderson, D.M., ed., 2002, Mosby's Medical Nursing \& Allied Health Dictionary, 6th edn., Mosby, London.

Booyens, S.W., 2001, Introduction to Health Services Management, 2nd edn., Juta, Cape Town.

Booyens, S.W., 1998, Dimensions of Nursing Management, 2nd edn., Juta, Cape Town.

Burns, N. \& Grove, S.K., 2007, Understanding nursing research. Building an evidencebased practice, 4th edn., Saunders Elsevier, St Louis.

Couper, I.D., 2004, Seeking quality: some experiences in South Africa, viewed 4 April 2010, from http://www.rrh.org.au/publishedarticles/article print $271 \mathrm{pdf}$

Couper, I.D., Thurley, J.D. \& Hugo, J.F., 2005, The neonatal resuscitation training project in rural South Africa, viewed 4 April 2010, from http://www.rrh.org.au/ publishedarticles/article print 459.pdf

Courtney, M., Yacopetti, J., James, C., Walsh, A. \& Finlayson, K., 2002, 'Comparison of roles and professional development needs of nurse executives working in metropolitan, provincial, rural or remote settings in Queensland', Australian metropolitan, provincial, rural or remote settings in Queensland, Australian
Journal Rural Health 10(4):202-08. http://dx.doi.org/10.1046/j.14401584.2002.00439.x, PMid:12121410

Cullinan, K., 2006, 'Health services in South Africa: A basic introduction', in Health-e News Service, viewed 12 April 2010, from http://www.health-e, org.2a

Deaton, B.J., Essenpreis, H. \& Simpson, K.R., 1998, 'Assessing Competence. Meeting the unique needs of nurses in small rural hospitals', AWHONN Lifelines 2(5), 3337.

Department of Health, 1999, A patients' rights charter, Government Printer, Pretoria.

Department of Public Service and Administration, 1997, White Paper on Transforming Public Service Delivery (Batho Pele White Paper) of the public service and administration, Government Printer, Pretoria.

De Villiers, M.R., 2004, Doctor's view of working conditions in rural hospitals in the Western Cape, viewed 4 April 2010, from http://www.safpj.co.za/index.php/ safpj/article/viewfile/46/46/

Donabedian, A., 1990, 'The seven pillars of quality', Arch Pathol Lab Med 114 (November), 1115-1118. PMid:2241519

Donabedian, A., 1980, Explorations in quality assessment and monitoring: The definition of quality and approaches to its assessment, Ann Arbor, Health Administration.

Eygelaar, J.E., 2009, 'An investigation into factors influencing the quality of nursing care in district hospitals in the West Coast Winelands Region of the Wester Cape', MCur thesis, Division of Nursing, Faculty of Health Sciences, Stellenbosch University. 
Kenny, A. \& Duckett, S., 2003, 'Educating for rural nursing practice', Journal of Advanced Nursing 44(6), 613-620, viewed 12 April 2010, from http://www3. interscience.wiley.com/journal/118883618/abstract

Lee, J. \& Winters, C.A., 2006, Rural nursing: concepts, theory and practice, 2nd edn., Springer, New York.

Polit, D.F. \& Beck, C.T., 2008, Nursing Research: Generating and Assessing Evidence for Nursing Practice, 8th edn., Lippincott, London.

Richardson, K.A., 2011, 'The impact of retiring baby boomers on nursing shortage', Journal of Global Health Care Systems 1(1), 1-16.

Roussel, L. \& Swansburg, R.C., 2009, Management and leadership for nurse administrators, 5th edn., Jones \& Bartlett, Massachusetts.

Searle, S., 2000, Professional practice. A Southern African nursing perspective, 3rd edn., Heinemann, Pinetown.

Searle, S., 2005: Professional practice. A Southern African nursing perspective, 4th edn., Heinemann, Pinetown.

Shongwe, N.T., 2000, Quality Assurance: An evaluation of the quality of nursing care in Swaziland, UNISA, Pretoria.

Solidarity Research Institute, 2009, Nurse shortage in South Africa. Nurse/Patient ratios Report May 2009, viewed 9 March 2010, from www.solidarity.co.za

Republic of South Africa, 2005, Nursing Act (Act 33 of 2005), Government Printer, Pretoria.

Republic of South Africa, 1996, The Constitution of the Republic of South Africa Act (Act 106 of 1996), Pretoria, Government Printer.
Republic of South Africa, 1978, Nursing Act (Act 50 of 1978). Pretoria: Government Printer.

Republic of South Africa, 1978, The Scope of Practice, Regulation 2598 as promulgated by the Nursing Act (Act 50 of 1978), Government Printer, Pretoria.

Republic of South Africa, 1978, Acts and Omissions Regulation 387, as promulgated by the Nursing Act (Act 50 of 1978), Pretoria, Government Printer.

Rural Doctors Association of South Africa, 2008, 'A strategy to enhance health services in rural and other deprived areas', South African Demographic and Health Survey 2008, viewed 17 March 2010, from http://www.rudasa.org.za/download/ ruralhealthstrat 50808.pdf

Uys, C., 2004, 'Quality management: Barriers and enablers in a curative primary health care service', Masters thesis, Dept of Health Studies, University of South Africa, Pretoria.

Wildschut, A. \& Mqolozana, T., 2008, Case Study, Forming part of the Human Science Research Council Study: A multiple source identification and verification scarce and critical skills in the South African labour market, Human Sciences Research Council, Pretoria.

World Health Organization, 2002, 'Constitution' in Bull World Health Org 80(12), 2 , viewed 22 March 2010, from: http://www.scielosp.org/scielo.php?script=sci_ar ttext\&pid=S0042862002001200015\&lng=http://www.searo.who.int/LinkFiles/ About_SEARO_const.pdf

World Health Organization, 2009, Increasing access to health workers in remote and rural areas through improved retention, p. 3, WHO, Geneva.

Xego, S.W., 2006, 'Professional Nurses' experience of working in a rural hospital in the Eastern Cape Province', Master of Arts thesis, Dept of Health Studies, University of South Africa, Pretoria. 